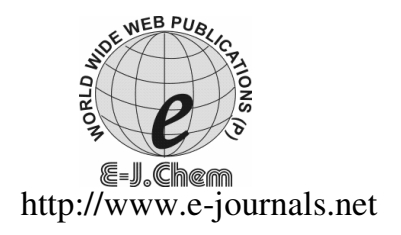

ISSN: 0973-4945; CODEN ECJHAO

E-Journal of Chemistry

2010, 7(4), 1440-1448

\title{
Optimization on Epoxidation of Palm Olein by Using Performic Acid
}

\author{
DARFIZZI DERAWI and JUMAT SALIMON* \\ School of Chemical Sciences and Food Technology, \\ Faculty of Science and Technology, Universiti Kebangsaan Malaysia, \\ 43600 UKM Bangi, Selangor Darul Ehsan, Malaysia. \\ jumat@ukm.my \\ Received 6 December 2009; Accepted 2 February 2010

\begin{abstract}
The epoxidation process of palm olein $\left(\mathrm{PO}_{\mathrm{o}}\right)$ was carried out by using in situ generated performic acid $(\mathrm{HCOOOH})$ to produce epoxidized palm olein (EPO). $\mathrm{HCOOOH}$ was produced by mixing of formic acid $(\mathrm{HCOOH})$ as oxygen carrier and hydrogen peroxide $\left(\mathrm{H}_{2} \mathrm{O}_{2}\right)$ as oxygen donor in various ratio of $\mathrm{PO}_{0}$ : $\mathrm{HCOOH}: \mathrm{H}_{2} \mathrm{O}_{2}$. The effect of $\mathrm{HCOOH}$ and $\mathrm{H}_{2} \mathrm{O}_{2}$ concentration, temperature, stirring effect and reaction time were studied. The presence of oxirane ring of EPO was characterised by fourier transformation infra-red (FTIR), proton and carbon nuclear magnetic resonance ( ${ }^{1} \mathrm{H}-\mathrm{NMR}$ and $\left.{ }^{13} \mathrm{C}-\mathrm{NMR}\right)$ spectra. The results showed that an optimum oxirane oxygen content (OOC) value was obtained by using mol ratio of 1:5:2 at 150 minutes.
\end{abstract}

Keywords: Palm olein, Epoxidation, Oxygen oxirane content, Oxirane ring.

\section{Introduction}

Palm olein $\left(\mathrm{PO}_{\mathrm{o}}\right)$ is a liquid fraction of palm oil (the largest renewable resources in Malaysia), consists of mainly mono-unsaturated triacylglycerol (TAG), POP (42.8\%) and $d i$-unsaturated TAG, POO (35.7\%). The iodine value ${ }^{1}$ of $\mathrm{PO}_{\mathrm{o}}$ is about $51.0-61.0$. Fats and oils are renewable resources that can be chemically or enzymatically modified to produce materials that can often act as a replacement for materials derived from petroleum ${ }^{2,3}$. Among the chemical modifications of polyolefins, epoxidation is a simple and efficient method for introducing a new reactive group and useful properties and wide use in a variety of applications ${ }^{4}$. Due to the high reactivity of the oxirane ring, epoxides can also act as raw materials for synthesis of a variety of chemicals, such as alcohols, glycols, alkanolamines, carbonyl compounds, olefinic compounds and polymers like polyesters, polyurethanes and epoxy $\operatorname{resin}^{5}$. Epoxidation using soybean oil for the synthesis of commercially valuable plasticizers and polymer stabilisers has already been successfully implemented at plant scale ${ }^{6,7}$. 
Epoxidized oil has been used widely as stabilizer and plasticizer in polyvinylchloride (PVC). Epoxidized ester can be used as solvent to replace the volatile organic solvent in paints. It also has been studied actively for lubricant production through the reaction of the epoxy group with linear or branching chain ${ }^{8}$.

The presence of $40.0 \%$ oleic acid in the $\mathrm{PO}_{\mathrm{o}}{ }^{9}$ is widely open for further reaction such as epoxidation process. The epoxidation process of $\mathrm{PO}_{\mathrm{o}}$ is not developed well yet. Kinetic study on the epoxidation and oxirane cleavage of methyl ester palm olein (MEPO) by using performic acid generated in situ as catalyst has been reported ${ }^{10}$. Performic acid has been used in the epoxidation process on fatty acid methyl ester (FAME) of soybean ${ }^{11}$. High epoxidation yield was obtained at $40{ }^{\circ} \mathrm{C}$ with using high concentration of hydrogen peroxide (60 wt \%). A study on partial and fully epoxidation of plant oils with perhydrolysis lipase as catalyst has been reported ${ }^{12}$. Epoxidation of unsaturated plant oils conducted in industrial process by Prileshajev-epoxidation using short chain peroxy acid generated in situ. Novozym ${ }^{\circledR} 435$ and hydrogen peroxide have been used to epoxidize the unsaturated plant oils and over than $90 \%$ of conversion was obtained ${ }^{12}$.

Epoxidations are commonly carried out using a peracid (peroxy acid), either preformed or formed in situ, by reacting a carboxylic acid (usually acetic acid) as oxygen carrier with concentrated hydrogen peroxide $\left(\mathrm{H}_{2} \mathrm{O}_{2}\right)$ as oxygen donor ${ }^{13}$. Formic acid is preferred to acetic acid as oxygen carrier because, owing to its high reactivity, no catalyst is required in the formation of performic acid ${ }^{14}$, but the production costs increase because formic acid's price is frequently higher than acetic acid's price ${ }^{13}$.

To achieve a high OOC value of epoxide, there were some parameters that we have to consider such as concentration of peroxy acid (epoxidation agent), reaction temperature, reaction time and stirring speed. An increasing in the peroxy acid content of the reaction mixture is accompanied by an increase of oxirane oxygen content (OOC) value. For a reaction mixture containing a fixed amount of vegetable oil (double bonds), there may be a concentration of acid (oxygen carrier) required for optimum epoxidation, beyond which oxirane cleavage (epoxide degradation) may become important ${ }^{15}$. The epoxidation rate increased as the concentration of $\mathrm{H}_{2} \mathrm{O}_{2}$ in the system increased. But, the stability of the oxirane ring was very poor at this high mole ratio of $\mathrm{H}_{2} \mathrm{O}_{2}$. On the other hand, at low concentrations of $\mathrm{H}_{2} \mathrm{O}_{2}$, oxirane ring was quite stable ${ }^{5}$. Some of authors reported that the oxirane formation rate increased when the stirring speed increased until moderate stirring speed, but was not substantially affected by stirring speeds beyond moderate stirring speed, and hence, it was assumed that the reaction was free from mass transfer resistance under the given condition ${ }^{13,5}$. For the temperature parameter, there found that as temperature increased, the epoxidation rate increased. At lower temperatures, the relative percentage conversion to oxirane continuously increased within the experimental time limit. However, at higher temperature, the relative percentage conversion to oxirane attained a maximum, after which it gradually decreased. The OOC value showed a continuous decrease beyond the moderate temperature, that may lead to severe degradation ${ }^{13,5}$. Reaction time played a role as the variable in order to obtain the optimum condition of a reaction by integrating with other parameters. Beyond the optimum reaction time of a parameter, the OOC value of epoxide decreased rapidly.

In this paper, we report that the effect of $\mathrm{HCOOH}$ and $\mathrm{H}_{2} \mathrm{O}_{2}$ concentration, temperature, reaction time and stirring condition during the epoxidation of $\mathrm{PO}_{\mathrm{o}}$ and the oxygen oxirane content (OOC) values of epoxidized palm olein (EPO) were monitored. Detection tests done in order to prove the present of oxirane ring of EPO. 


\section{Experimental}

Palm olein (Seri Murni brand, FFM Marketing Sdn. Bhd.) was used as raw material in this study. Formic acid (99\%) and hydrogen peroxide (30\%) were purchased from Univar and J. T. Baker.

The epoxidation reactions were carried out with some modifications, in a three necked glass $(250 \mathrm{~mL}$ capacity) flask equipped with a mechanical stirrer, thermometer and reflux condenser ${ }^{11,4} .50 \mathrm{~g}$ of $\mathrm{PO}_{\mathrm{o}}$ was weighed and mixed into the three necked glass. Under continuous stirring, the $\mathrm{PO}_{\mathrm{o}}$ was acidified with formic acid, and then hydrogen peroxide was slowly added drop wise. Fast introduction to this reagent will cause an excessive development of oxygen due to the decomposition of $\mathrm{H}_{2} \mathrm{O}_{2}$ at high temperature and is not recommended ${ }^{4}$. After the reaction finished, samples of reaction mixture were taken out and thoroughly washed with sodium bicarbonate $(5 \mathrm{wt} \%)$, distilled water and sodium chloride $(5 \mathrm{wt} \%)$ to separate the organic layer from the mixture. The sample was then analyzed for $\mathrm{OOC}$ value and iodine value respectively. Epoxidation was carried out at various mol ratios of $\mathrm{HCOOH}$ and $\mathrm{H}_{2} \mathrm{O}_{2}$, temperatures $\left(45,55,65^{\circ} \mathrm{C}\right)$ and undergo various stirring conditions (slow, moderate, fast).

Detection tests done by using fourier transformation infra-red (FTIR), carbon and proton nuclear magnetic resonance $\left({ }^{13} \mathrm{C}\right.$ NMR and $\left.{ }^{1} \mathrm{H} \mathrm{NMR}\right)$ in order to detect the oxirane ring of EPO. Oygen oxirane content (OOC) value was determined by direct method using hydrobromic acid solution in glacial acetic acid (AOCS Cd 9-57) ${ }^{16,17}$. The percentage of conversion can be calculated based on the theoretical $\mathrm{OOC}$ value of $\mathrm{PO}_{0}^{3,9}$. While, iodine value was determined according to Wijs method (BS 684: Section 2.13:1976) ${ }^{18}$. Characterization of EPO done by using kinematic viscosity and dynamic viscosity test method (ASTM D 445-79).

\section{Results and Discussion}

Various mol ratio of $\mathrm{PO}_{0}$ : $\mathrm{HCOOH}: \mathrm{H}_{2} \mathrm{O}_{2}$ (1:2: 4, 1: 5: 4 and 1: 9: 4) were studied to form the EPO. Formic acid acts as a catalyst in the formation of oxirane ring and as a reactant in the hydrolysis of the oxirane ring. To attain the maximum OOC value, the optimum amount of acid should be used where both will affects the amount of performic acid produced. Figure 1 shows the rate of epoxidation increased as the concentration of $\mathrm{HCOOH}$ in the system increased. The maximum OOC value $(3.63 \%)$ of EPO was obtained at 150 minutes for the reaction using mole ratio of $1: 5: 4$. The percentage of conversion was calculated of $97.1 \%$. For mol ratio of 1: 9: 4 , the OOC value obtained decreased rapidly after 120 minutes of reaction. The iodine value of EPO shown is in Figure 2. It shows that the initial iodine value of $\mathrm{PO}_{\mathrm{o}}$ (61.67) was rapidly decreased after the reaction. Iodine value for mol ratio of 1: 5: 4 at 150 minutes of reaction was the lowest value obtained. This is due to the fully epoxidation that occurred at this reaction condition and all of double bonds that have been converted to oxirane ring. Figure 3 shows that the OOC value was increased as the concentration of $\mathrm{H}_{2} \mathrm{O}_{2}$ increased. The results showed that the mol ratio of 1: 5: 2 gave almost the same OOC values (3.61\%) compared to the mol ratio of 1: $5: 4$ with $96.5 \%$ of conversion. The OOC value was observed for mol ratio of 1: 5: 6 had decreased compared to both mol ratios. The stability of the oxirane ring for this reaction condition was poor. The epoxidation process was exothermic and high concentration of peroxy acid must be avoided ${ }^{8,19}$. The effect of $\mathrm{H}_{2} \mathrm{O}_{2}$ concentration on iodine value of EPO has been shown in Figure 4. From the figure, the iodine value 
reached almost 0 for mol ratio of $1: 5: 2$ and $1: 5: 4$. This might be full conversion of double bonds to oxirane rings that has occurred. The reaction rate increased as the concentration of hydrogen peroxide in the system increased. But, the stability of the oxirane ring was very poor for the high concentration of $\mathrm{H}_{2} \mathrm{O}_{2}$. For higher $\mathrm{H}_{2} \mathrm{O}_{2}$ concentrations at the same temperature, the relative conversions to oxirane decreased more rapidly ${ }^{20}$.

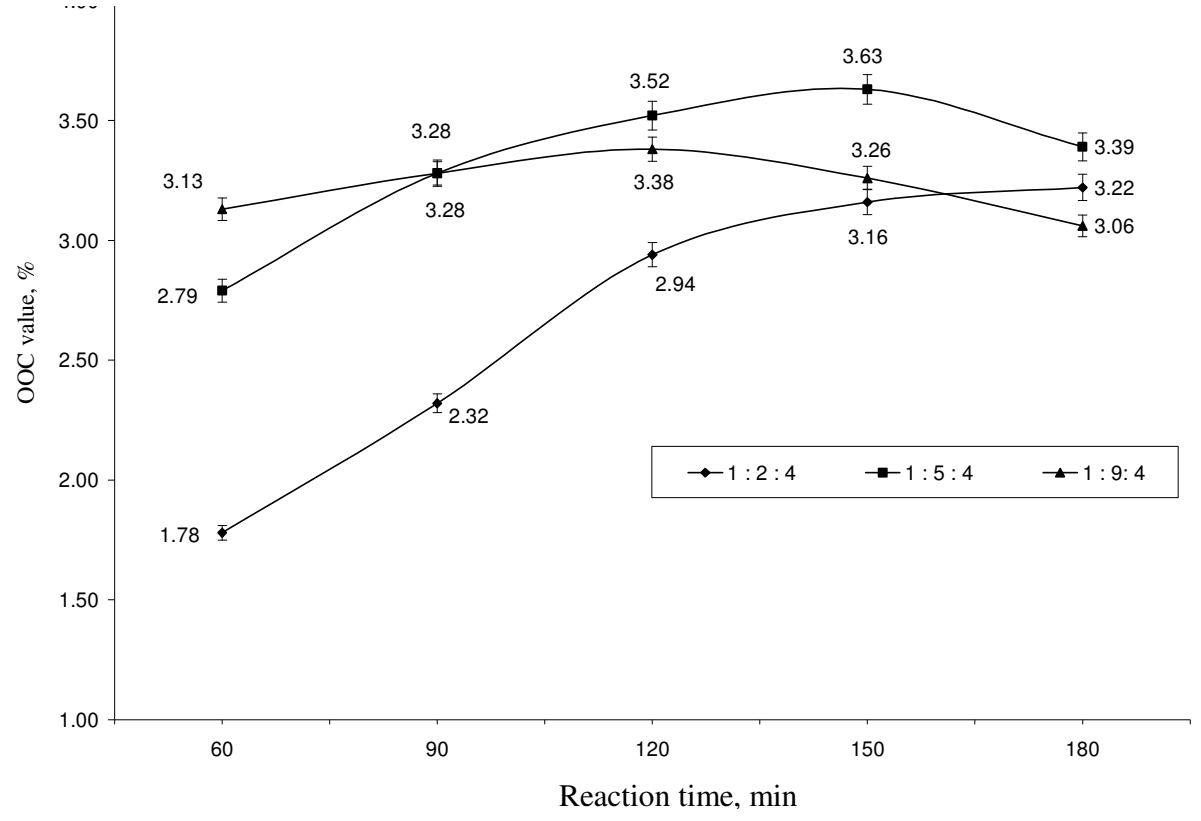

Figure 1. Concentration effect of $\mathrm{HCOOH}$ on $\mathrm{OOC}$ value of EPO

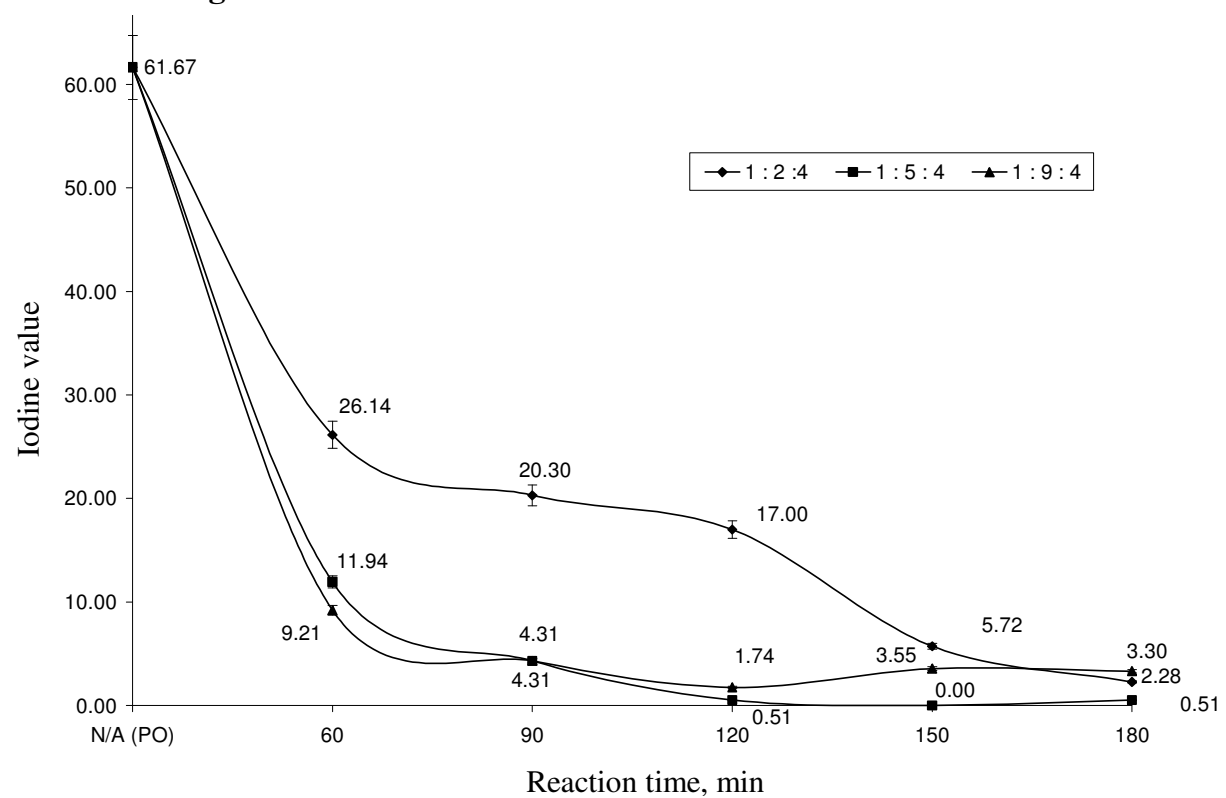

Figure 2. Concentration effect of $\mathrm{HCOOH}$ on iodine value of EPO 


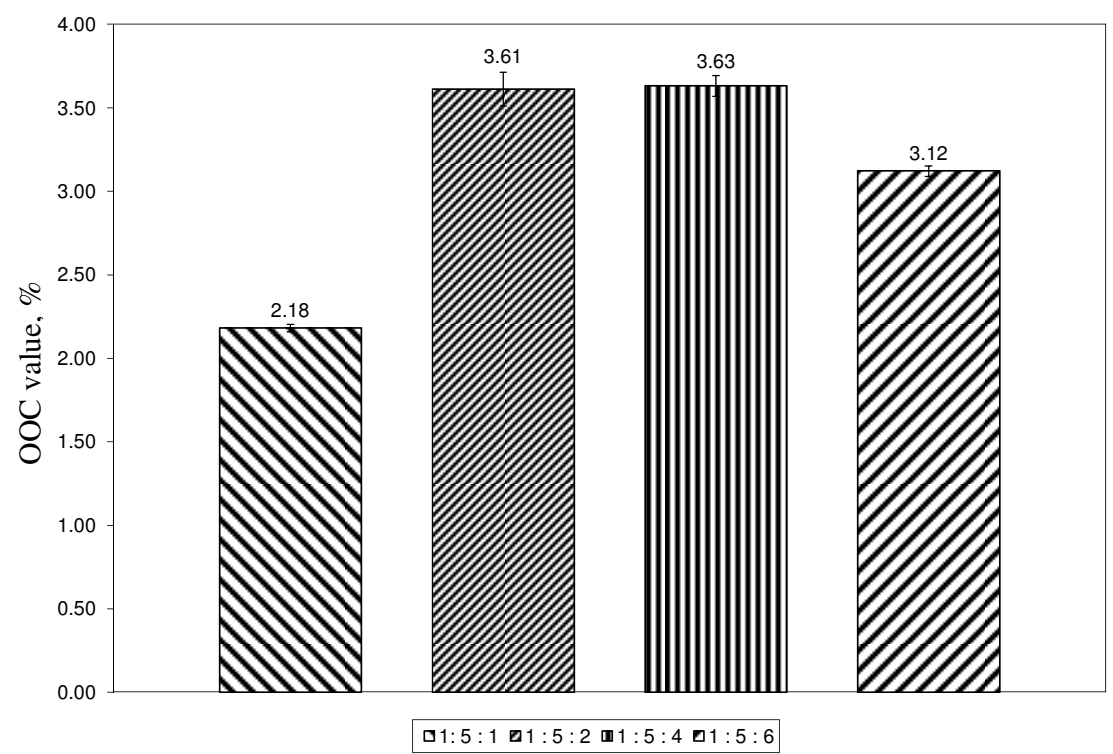

Figure 3. Concentration effect of $\mathrm{H}_{2} \mathrm{O}_{2}$ on OOC value of EPO

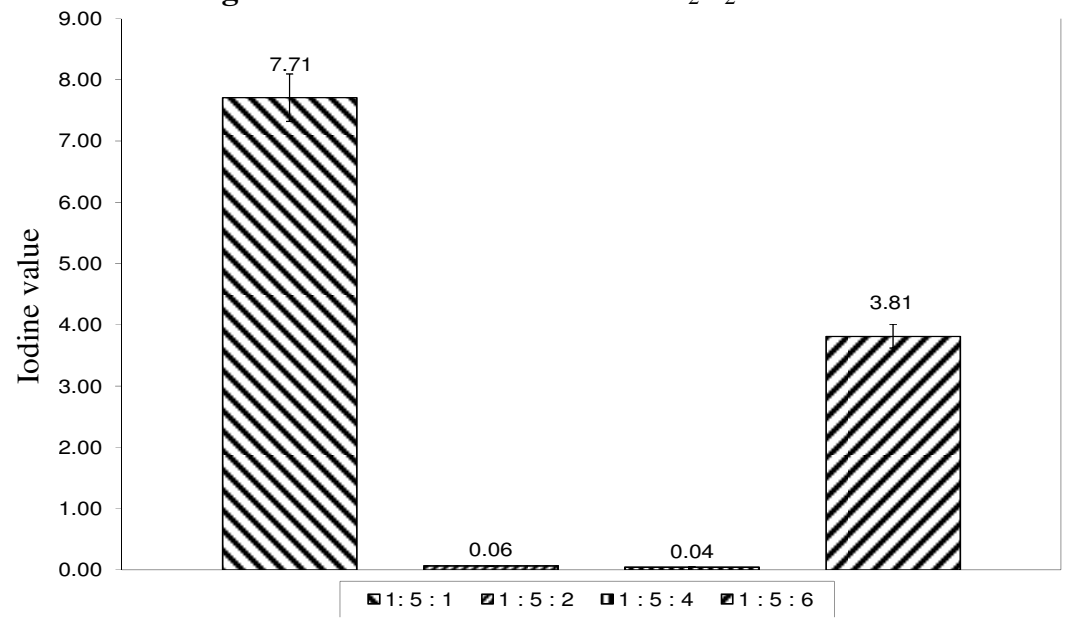

Figure 4. Concentration effect of $\mathrm{H}_{2} \mathrm{O}_{2}$ on iodine value of EPO

Increasing temperature showed a favourable effect on the formation of peracetic acid. This resulted not only shown in more rapid epoxidation, but also in higher rate of hydrolysis (oxirane cleavage) of the product ${ }^{20,3}$. Reaction at lower temperatures gave lower epoxidation rate but led to lesser ring opening ${ }^{5}$. The time required for attainment of the maximum OOC value at different temperatures $\left(45,55,65^{\circ} \mathrm{C}\right)$ is shown in Figure 5 . Reaction at lower temperature $\left(45^{\circ} \mathrm{C}\right)$ showed lower OOC value in the beginning of reaction but gave more stable oxirane ring after $90 \mathrm{~min}$ of reaction. Meanwhile, others showed a decreasing trend of their OOC value after 60 minutes of reaction. These results suggest that optimum levels of epoxidation could be attained at low reaction temperatures $\left(45^{\circ} \mathrm{C}\right)$ at which epoxide degradation would be minimal. 


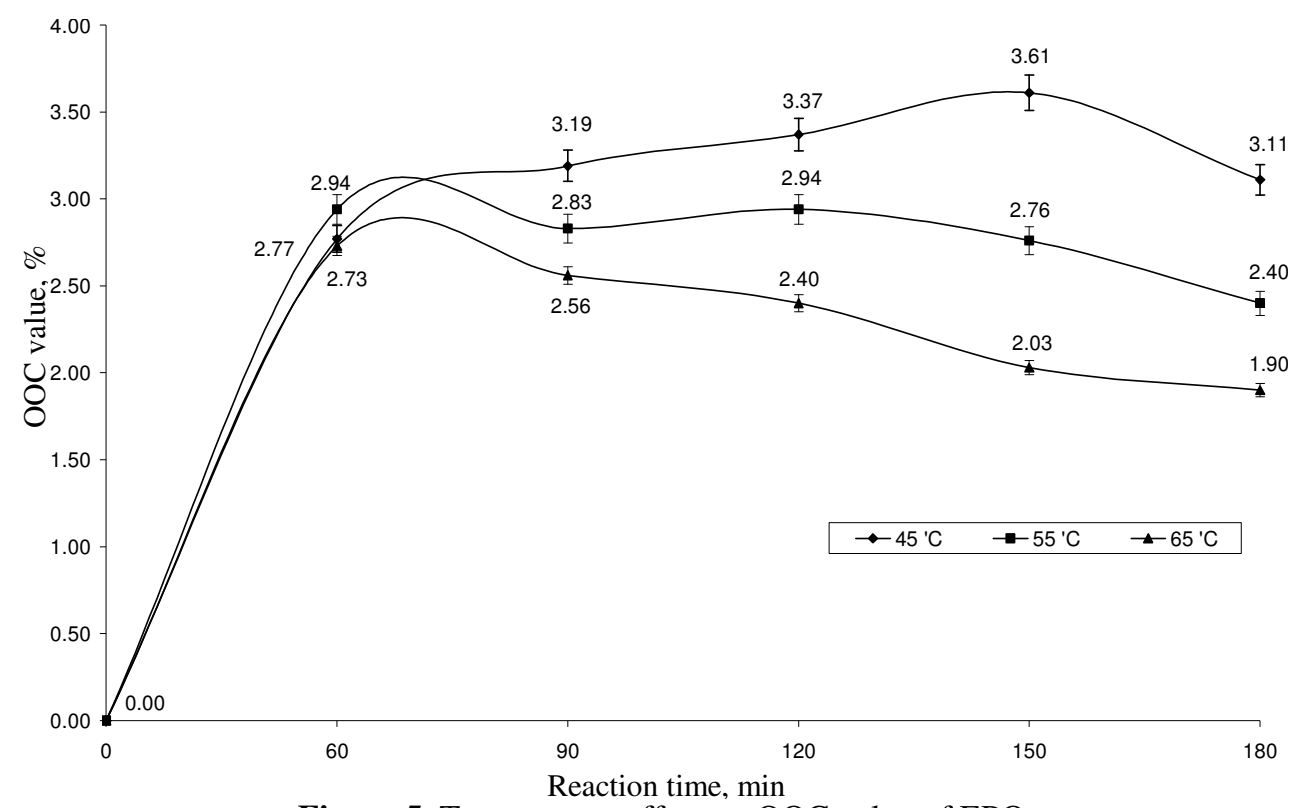

Figure 5. Temperature effect on OOC value of EPO

To investigate the effect of stirring speed on OOC value of EPO, reactions were carried out over of three different of stirring conditions which are 125, 350 and $650 \mathrm{rpm}$ as shown in Figure 6. It was observed that the unsaturation conversion of $\mathrm{PO}_{\mathrm{o}}$ as well as the oxirane oxygen formation increased with an increase in stirring speed. The OOC value for $125 \mathrm{rpm}$ was slightly maintained in a range of reaction time and the $\mathrm{OOC}$ value at $350 \mathrm{rpm}$ was increasing rapidly and achieved the highest value. Beyond $350 \mathrm{rpm}$, there was also decreasing in oxirane oxygen formation. It was assumed that the reaction was free from mass transfer resistance under the given conditions ${ }^{5,21,20}$. Hence, the subsequent experiments were performed at $350 \mathrm{rpm}$ of stirring speed.

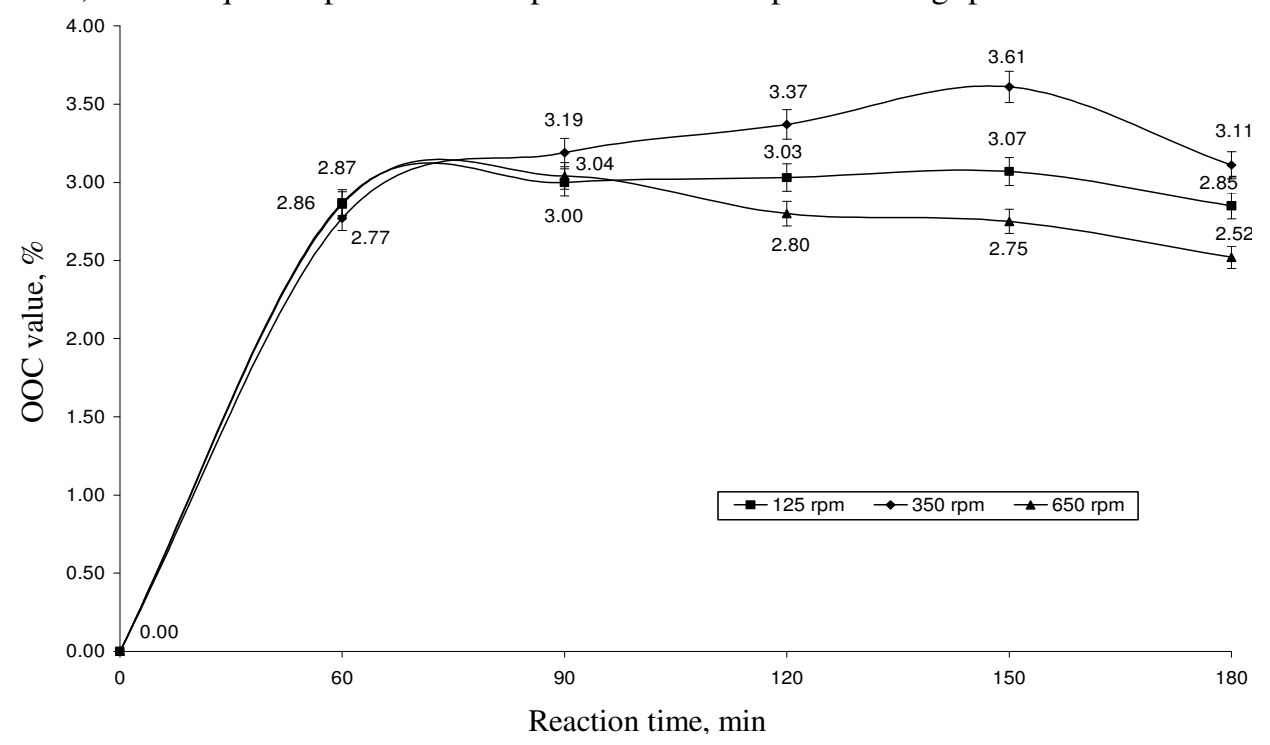

Figure 6. Stirring condition effect on OOC value of EPO 
In order to prove the present of oxirane ring of EPO, final product was tested by FTIR, ${ }^{13} \mathrm{C}$ NMR and ${ }^{1} \mathrm{H}$ NMR. The comparison between $\mathrm{PO}_{\mathrm{o}}$ and EPO FTIR spectra is shown in Figure 7. The data of ${ }^{13} \mathrm{C}-\mathrm{NMR}$ and ${ }^{1} \mathrm{H}-\mathrm{NMR}$ spectra are shown in Table 1 and 2. Oxirane ring can be detected at wavenumber $750-880 \mathrm{~cm}^{-1}$ and $815-950 \mathrm{~cm}^{-1}$, while overtone streching vibration peak of $\mathrm{C}=\mathrm{O}$ for ester at wavenumber $\sim 3450 \mathrm{~cm}^{-1}$, streching vibration peak of $=\mathrm{CH}$ can be detected at wavenumber $3050-3000 \mathrm{~cm}^{-1}$ and bonding peak of $\mathrm{HC}=\mathrm{CH}$ (cis) at wavenumber ${ }^{22} 1650-1600 \mathrm{~cm}^{-1}$. Based on Figure 7, FTIR spectrum of $\mathrm{PO}_{\mathrm{o}}$ showed an overtone streching vibration peak of $\mathrm{C}=\mathrm{O}$ for ester at wavenumber $3473 \mathrm{~cm}^{-1}$, streching vibration peak of $=\mathrm{CH}\left(3003 \mathrm{~cm}^{-1}\right)$ and bonding peak of $\mathrm{HC}=\mathrm{CH}$ (cis) at wavenumber $1651 \mathrm{~cm}^{-1}$. While, for the FTIR spectrum of EPO, the unsaturation peak and streching vibration peak of $=\mathrm{CH}$ for $\mathrm{PO}_{\mathrm{o}}$ have been disappeared. But the presents of oxirane ring peak was detected at wavenumber $844 \mathrm{~cm}^{-1}$. Based on Table 1 and 2, the presents of oxirane ring can be confirmed by comparision with teoritical ${ }^{13} \mathrm{C}$ and ${ }^{1} \mathrm{H}$ chemical shift ranges $(\mathrm{ppm}) \cdot{ }^{13} \mathrm{C}$ chemical shift ranges for unsaturated bond was $100-150 \mathrm{ppm}$ while for $\mathrm{C}-\mathrm{O}$ was $40-80 \mathrm{ppm}$. ${ }^{1} \mathrm{H}$ chemical shift ranges for vinyl hydrogen $(\mathrm{C}=\mathrm{C}-\mathrm{H})$ was $4.5-6.5 \mathrm{ppm}$ and for allyic hydrogen $(\mathrm{C}=\mathrm{C}-\mathrm{C}-\mathrm{H})$ was $1.6-2.6 \mathrm{ppm}$ while for epoxide appeared in the range $2.5-3.5 \mathrm{ppm}^{23}$.

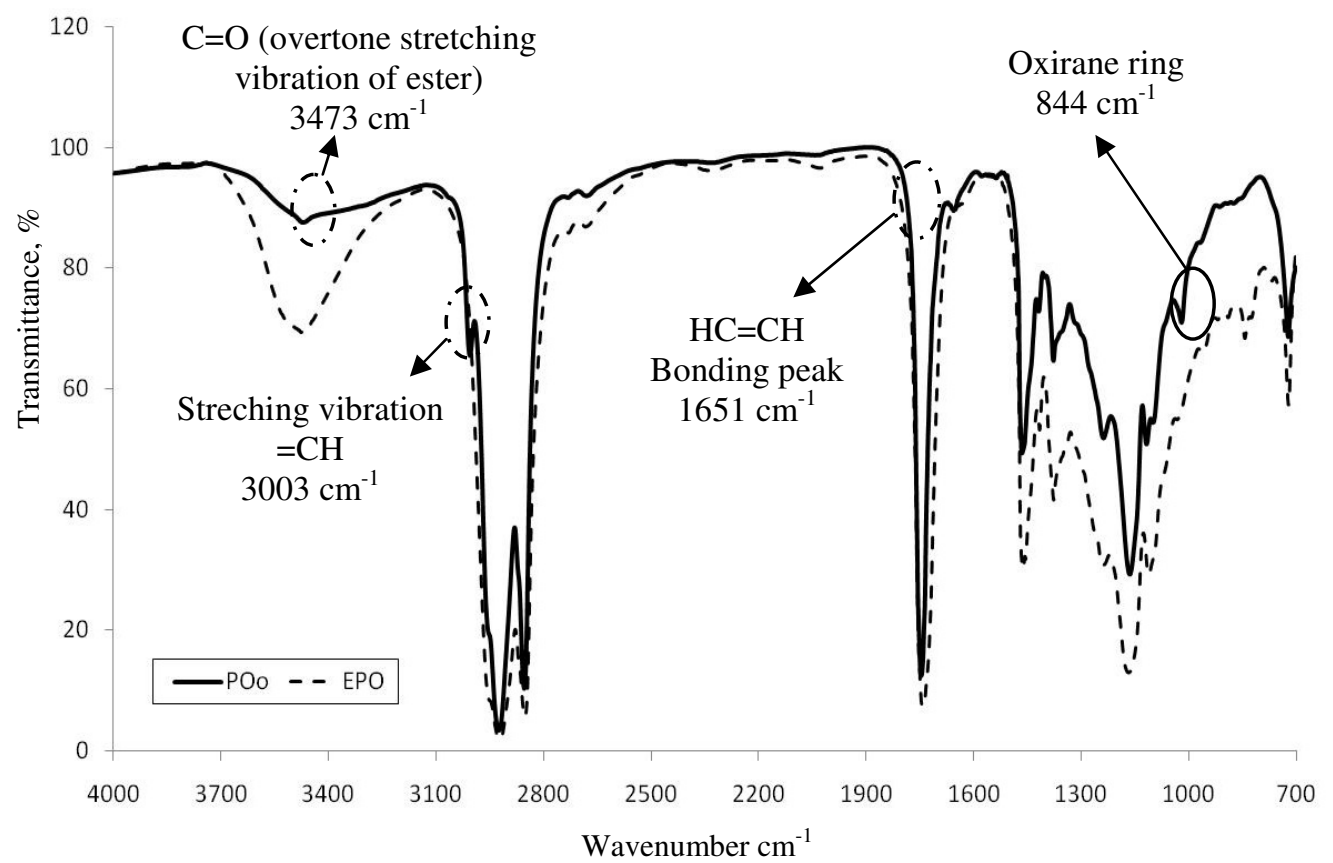

Figure 7. Comparision FTIR spectra between $\mathrm{PO}_{\mathrm{o}}$ and EPO

Table 1. Comparison data between ${ }^{13} \mathrm{C}-\mathrm{NMR} \mathrm{PO}_{\mathrm{o}}$ and EPO

\begin{tabular}{clcc}
\hline Compound & Chemical shifts, ppm & $\begin{array}{c}\text { Chemical shift, ppm } \\
\left.\text { (Theoretical }^{23}\right)\end{array}$ & Conclusion \\
\hline $\mathrm{PO}_{\mathrm{o}}$ & $\begin{array}{l}130.3761,130.1697, \\
129.8638,129.8409\end{array}$ & $100-150$ & $\mathrm{C}=\mathrm{C}$ \\
$\mathrm{EPO}$ & $\begin{array}{l}57.3681,57.3070, \\
54.4778\end{array}$ & $40-80$ & $\mathrm{C}-\mathrm{O}$ \\
\hline
\end{tabular}


Table 2. Comparison data between ${ }^{1} \mathrm{H}-\mathrm{NMR} \mathrm{PO}_{\mathrm{o}}$ and $\mathrm{EPO}$

\begin{tabular}{|c|c|c|c|}
\hline Compound & Chemical shifts, ppm & $\begin{array}{c}\text { Chemical shift, ppm } \\
\left(\text { Theoretical }{ }^{23}\right)\end{array}$ & Conclusion \\
\hline $\mathrm{PO}_{\mathrm{o}}$ & $\begin{array}{l}5.3763,5.3625,5.3543, \\
5.3479,5.3406,5.3314, \\
5.2801,5.2691,5.2545\end{array}$ & $4.5-6.5$ & $\begin{array}{c}\mathrm{C}=\mathrm{C}-\mathrm{H} \\
\text { (vinyl hydrogen) }\end{array}$ \\
\hline & $\begin{array}{l}2.0772,2.0608, \\
2.0205,2.0058\end{array}$ & $1.6-2.6$ & $\begin{array}{c}\mathrm{C}=\mathrm{C}-\mathrm{C}-\mathrm{H} \\
\text { (allyic hydrogen) }\end{array}$ \\
\hline EPO & $\begin{array}{l}2.9030 \\
1.4907,1.4513\end{array}$ & $\begin{array}{l}2.5-3.5 \\
1.4-1.7\end{array}$ & $\begin{array}{l}\text { Epoxides } \\
\mathrm{R}_{3} \mathrm{CH}\end{array}$ \\
\hline
\end{tabular}

An economically optimum epoxidation of palm olein using in situ generated performic acid could be carried out at mol ratio of $1: 5: 2\left(\mathrm{PO}_{\mathrm{o}}: \mathrm{HCOOH}: \mathrm{H}_{2} \mathrm{O}_{2}\right)$ at $350 \mathrm{rpm}$ of stirring speed and $45{ }^{\circ} \mathrm{C}$ for $150 \mathrm{~min}$. A high yield of oxygen oxirane content value was $3.61 \%( \pm 2.8 \%)$ with $96.5 \%$ of conversion. The density of EPO was $0.886 \mathrm{~g} \mathrm{~mL}^{-1}$ while its kinematic viscosity was $358.1 \mathrm{cSt}$ and dynamic viscosity was $317.3 \mathrm{cP}$.

\section{Conclusion}

Based on optimum reaction condition in this study, a high yield of oxygen oxirane content value $(3.61 \%)$ was obtained and this value almost same with the theoretical value $(3.74 \%)$ with $96.5 \%$ of conversion. The reaction yield was $91.3 \%$.

\section{Acknowledgments}

The authors would like to thanks to the Universiti Kebangsaan Malaysia for the financial support via research grant no. UKM-GUP-NBT-08-27-113, UKM-OUP-NBT-29-150/2010 and Ministry of Science, Technology and Innovation (MOSTI) for the National Science Fellowship (NSF) scholarship support.

\section{References}

1. O'Brien R D, Fats and Oils, Formulating and Processing for Applications, Technomic Publishing AG: Switzerland, 1998.

2. Gan L H, Ooi K S, Gan L M and Goh S H, J Am Oil Chem Soc., 1995, 72, 439-442.

3. Goud V V, Patwardhan A V and Pradhan N C, Biores Technol., 2006, 97, 1365-1371.

4. Wang X, Zhang H, Wang Z and Jiang B, Polymer, 1997, 38(21), 5407-5410.

5. Dinda S, Patwardhan A V, Goud V V and Pradhan N C, Biores Technol., 2008, 99, 3737-3744.

6. Biermann U, Friedt W, Lang S, Luhs W, Machmuller G, Metzger J O, Klaas M R, Schafer H J and Schneider M P, Angew Chem Int., 2000, 39, 2206-2224.

7. Wallace J C, Determination of Organic Compounds: Methods and Procedures; Wiley Interscience: New York, 1978.

8. Gunstone F D, The Chemistry of Oils and Fats: sources, composition, properties and uses; Blackwell Publishing Ltd., UK, 2004.

9. Scrimgeour C, Chemistry of Fatty Acids; $6^{\text {th }}$ Ed.; John Wiley \& Sons, Inc.: Scotland, 2005.

10. Gan L H, Goh S H and Ooi K S, J Am Oil Chem Soc., 1992, 69(4), 347-351.

11. Campanella A, Fontanini C and Baltanás M A, Chem Eng J., 2008, 144, 466-475.

12. Klaas M R and Warwel S, Ind Crops Prod., 1999, 9, 125-132.

13. Campanella A, Fontanini C and Baltanás M A, Catalysis Today, 2005, 107-108, 208-214. 
14. Scala J L and Wool R P, J Am Oil Chem Soc., 2002, 79, 59-63.

15. Okieimen F E, Bakare O I and Okieimen C O, Ind Crops Prod., 2002, 15, 139-144.

16. AOCS, Official Methods and Recommended Practices of AOCS, AOCS, Illionis, 1998.

17. Paquot C, Standard Methods for the Analysis of Oils, Fats and Derivatives Part- $1 ; 5^{\text {th }}$ Ed.; Pergamon Press: Germany, 1979.

18. Jumat S, Mamot S, Suria R and Mohamad Azwani Shah M L, Oils and Fats Analysis; Pusat Penerbitan dan Percetakan UKM, Bangi, 2006.

19. Gunstone F D and Padley F B, Lipid Technologies and Applications; Marcel Dekker, Inc., New York, 1997.

20. Goud V V, Patwardhan A V and Pradhan N C, J Am Oil Chem Soc., 2006, 83, 635-640.

21. Goud V V, Patwardhan A V, Dinda S and Pradhan N C, Chem Eng Sci., 2007, 62, 4065-4076.

22. Socrates G, Infrared and Raman Characteristic Group Frequencies; $3^{\text {rd }}$ Ed.; John Wiley \& Sons Ltd: England, 2001.

23. Pavia D L, Introduction to Spectroscopy; Thomson Learning, Inc., United States, 2001. 


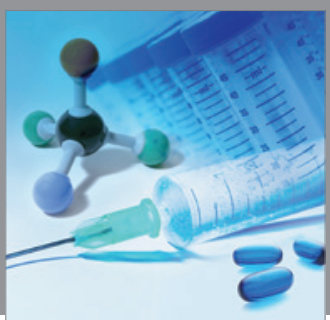

International Journal of

Medicinal Chemistry

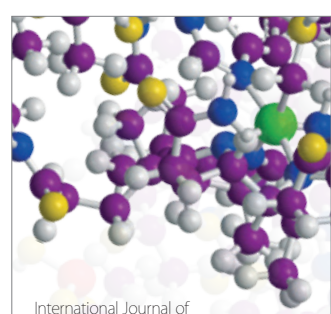

Carbohydrate Chemistry

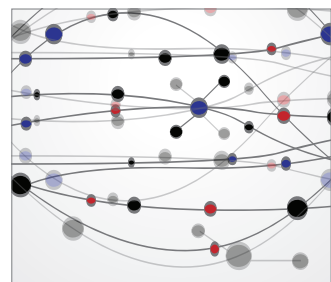

The Scientific World Journal
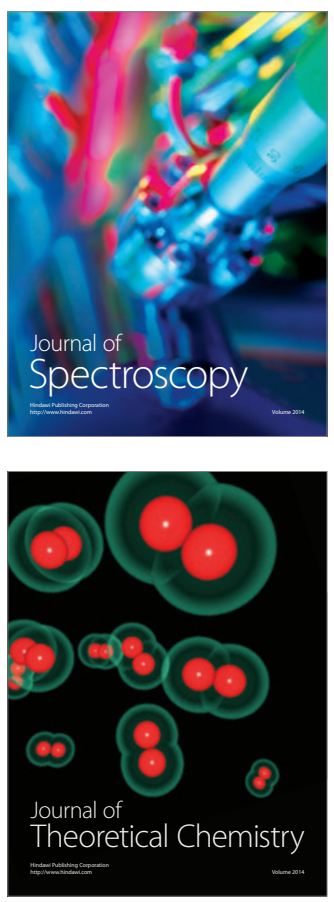
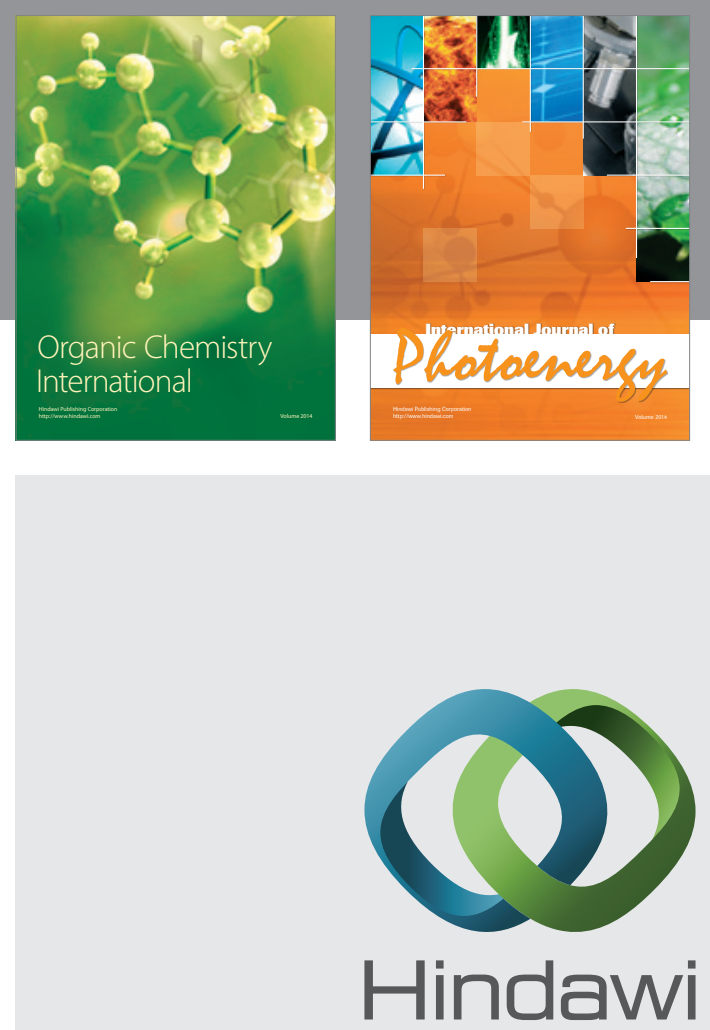

Submit your manuscripts at

http://www.hindawi.com
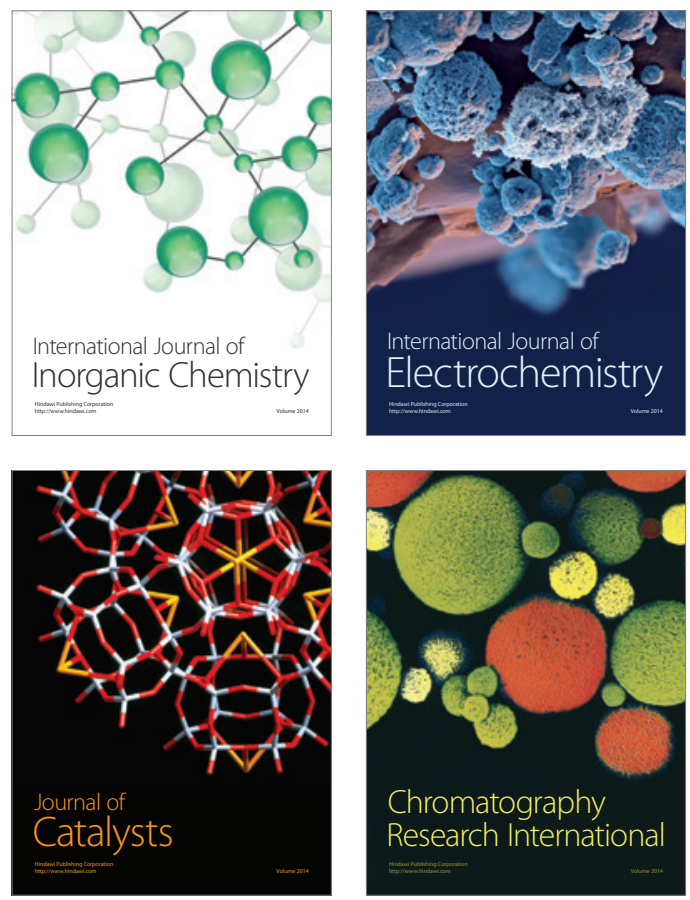
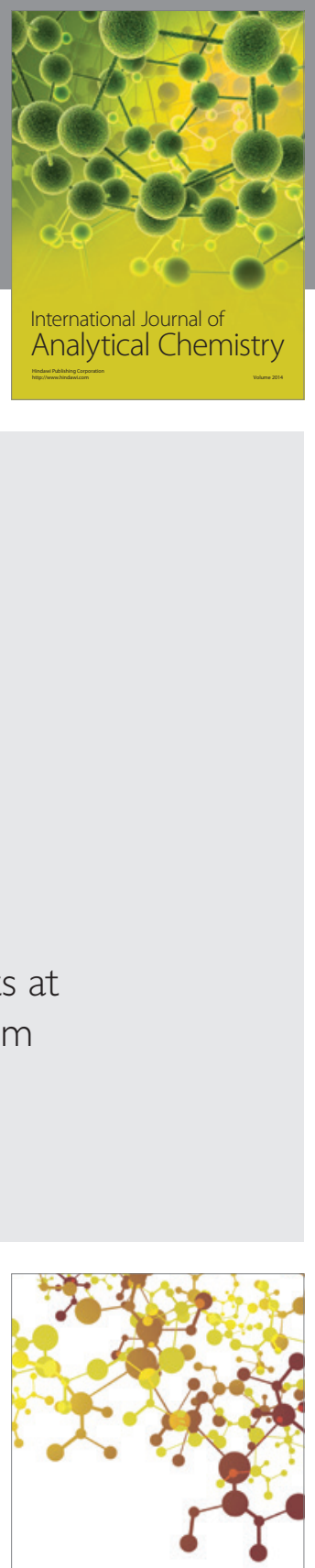

Journal of

Applied Chemistry
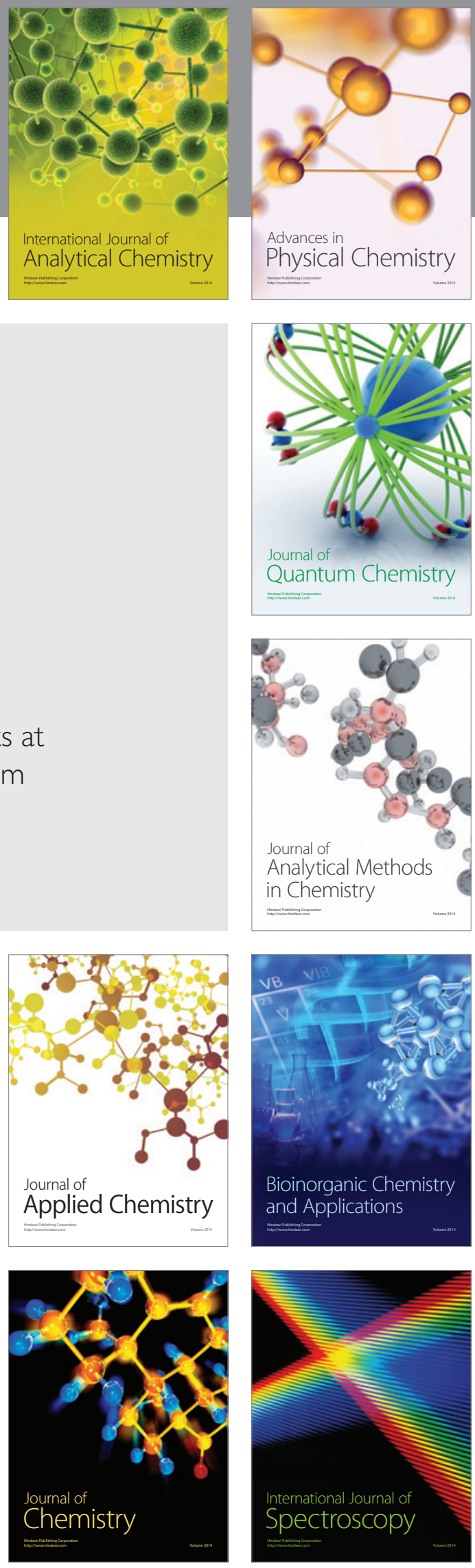